\title{
The Town Square in Your Pocket: Exploring Four Metaphors of Social Media
}

\author{
Daniel B. le Roux ${ }^{(凶)}(\mathbb{D}$ and Douglas A. Parry \\ Information Science, Stellenbosch University, Stellenbosch, South Africa \\ $\{$ dbleroux, dougaparry\}@sun.ac.za
}

\begin{abstract}
In this paper we explore the use of four metaphors as a means to illuminate particular dimensions of social media logic - the norms, strategies, and economics underpinning its dynamics. Our objective is to utilise metaphor to instigate critical reflection about the nature of social media use behaviour and the role of habitual social media use in our experiences of reality. The first metaphor, social media as a town square, draws attention to the centrality of social media platforms in their users' lives, fear of missing out, augmented reality and digital dualism. Through the second metaphor, social media as a beauty pageant, we explore self-presentation or image crafting, social comparison and selfevaluation. The third metaphor, social media as a parliament, emphasises the role of social media platforms as spaces for online deliberation and we consider social media capital, homophily and polarisation as themes. Finally, we explore anonymity, deindividuation and deceptive self-presentation through our fourth metaphor, social media as a masquerade ball. We argue that social media scholars can use these and other metaphors to enhance communication of their research findings. Additionally, we believe that social media metaphors can be powerful pedagogical and communication tools, particularly when working with students for whom high levels of social media use is the norm.
\end{abstract}

Keywords: Social media $\cdot$ Metaphor $\cdot$ Town square $\cdot$ Beauty pageant $\cdot$ Parliament $\cdot$ Masquerade ball

\section{Introduction}

It would be difficult to overstate the rapidity of the increase in agency that social media platforms have had in our sensemaking of the world. On a superficial level this agency is reflected in both the number of users on social media platforms and in the amount of time users spend on these platforms. However, the true impact of these technologies is perhaps most apparent in the way high levels of social media use have become enmeshed in our daily routines and, by extension, our ongoing experiences of reality. Obvious testament of the centrality that social media now occupy in our lives is the important role platforms like Facebook played in recent elections/referendums in the US and UK.

(C) IFIP International Federation for Information Processing 2020

Published by Springer Nature Switzerland AG 2020

M. Hattingh et al. (Eds.): I3E 2020, LNCS 12067, pp. 187-198, 2020.

https://doi.org/10.1007/978-3-030-45002-1_16 
A consequence of the habituation of social media use is that we run the risk of becoming desensitised to its role in shaping our subjective and social realities. In this paper we turn to metaphor as a means to counter this desensitisation and obtain a degree of objectivity about the underlying logic of social media use. As a linguistic and conceptual tool, metaphor has served, across the ages, as a powerful instigator of critical thinking in multiple domains [15]. Its value was emphasised by Aristotle who described its command as the mark of genius [15] and, in recent times, a substantial body of theoretical work and psychological studies directed at the process of metaphor comprehension has emerged $[15$, p. 641]. Franke [9], accordingly, argues that, in recent decades, the "fortunes of metaphor have revived and flourished in tandem with those of rhetoric as a whole". Central to this revival is a renewed appreciation of the important role of metaphor in human cognition.

Our primary objective in this paper is to utilise metaphor to instigate and facilitate critical reflection about social media logic - "the norms, strategies, mechanisms, and economics underpinning its dynamics" [6]. In principle, this is akin to the objective of Morgan [23] whose oft-cited book, Images of Organisation, has achieved broad recognition for its analysis of various metaphors of organisation to "explore and develop the art of understanding organisational life" [23, p. 4]. Our objective, similarly, is to explore and develop understanding of social media life through the analysis of specific metaphors of social media. We aim to achieve this by mapping selected properties from a set of selected source domains to properties of particular aspects of social media logic to produce creative and rich descriptions of this logic. These descriptions, we propose, offer a vantage point from which critical reflection and analyses may be performed.

We propose and briefly analyse four metaphors of social media. Importantly, we do not undertake systematic analyses of metaphors as they appear in some form of qualitative data source. Such analyses answer questions concerning the discourse about and social construction of a phenomenon by a particular collective, and "metaphors or metaphorical ideas are framed as mediators or artefacts at the social cultural level of discourse and cognition" which influence mind and behaviour [16, p. 206]. Our approach, rather, is to utilise particular source domains in an attempt to clarify complex ideas about social media logic. In doing so we hope to harness the ability of metaphors to create complexities which promote reflection leading to additional questioning and the clarification of concepts [34]. Ricoeur [30] argues that "metaphorical meaning does not merely consist of a semantic clash but of the new predicative meaning which emerges from the collapse of the literal meaning". It is our aim to, through exploration of this new predictive meaning, advance insight into social media logic.

\section{Defining Metaphor}

In accordance with Shen [33] we define a metaphor as "a selective mapping of properties between two (conceptual) domains, the source and the target". When we say that social media is like a party, we selectively map properties of 
a source or vehicle (a party) to a target or tenor (social media) [15, p. 644]. The metaphor operates on the basis of preexisting similarities between source and target, enabling the mapping of systematic correspondences between the source and target domains. This mapping, Lakoff [20] notes, permits us to reason about the target phenomenon by drawing on our knowledge and experience of the source domain. He argues, on this basis, that metaphors are not merely a matter of language, but that the ontological and epistemic mapping across domains is a matter of thought and reason. Metaphors have long been appreciated for playing a pedagogical role in science, helping to "sell new ideas by providing vivid or concrete relations and ways of representing those ideas" which, in turn, "sheds light on new features of an important phenomenon" [16, p. 199].

It is important to recognise and acknowledge the selective nature of sourcetarget mapping when applying metaphor. When proposing a metaphor, only a specific subset of source properties are mapped to the target - those that represent likeness between source and target. For example, parties involve social interaction and this property is mappable to social media. However, parties also take place at a particular place and time, properties that are not mappable to the target. Morgan [23], accordingly, argues that a metaphor, like any theory, is a partial, abstract truth rather than an absolute. A consequence of this principle is that a single target phenomenon can be described through the use multiple, different source domains, and vice versa. Additionally, in our analysis, we also consider differences or non-likeness between our proposed source domains and social media. It is our view that the recognition of both likeness and difference advances critical thinking about the target (i.e., social media logic).

Lastly, before commencing our analyses, it is worth briefly describing the process followed to identify the source domains we selected. Beyond this paper our primary area of interest concerns social media use patterns and, in particular, the effects of social media use for mental well-being. In discussions, seminars and lectures we have often found ourselves utilising metaphors informally to describe particular dimensions of social media logic. A growing appreciation of the communicative and pedagogical value of these metaphors encouraged us to develop a list of source domains that we have found to resonate with students and/or other audiences. The four metaphors we describe here were selected from that list and were chosen due to their emphases on different themes or discourses that are prominent in contemporary research on social media.

\section{Metaphors}

\subsection{Social Media as a Town Square}

The notion that social media platforms are like physical spaces is implicit in much of our informal language about it. When someone states that they are on Twitter or that they left Instagram, the metaphor is invoked. The primary purpose of the Town Square metaphor, accordingly, is to frame social media as somewhere one can go, be and leave, and as a location or setting where events can occur. We use as source domain the notion of a village town square, a central place where 
events of importance occur and which serves as a meeting point characterised by continuous social interactions. The town square, typically located in or close to the centre of the village, is easily and always accessible, mirroring the ubiquitous and pervasive nature of social media. Of course, in reality, the events that are mediated through social media occur across time space, but the medium, through its collation of content into streams, pages, groups etc., centralises the digital traces of dispersed events into a single online place. When combined in this way, the disparate digital cues become perceived as a new whole, which, in turn, gives new meaning to its parts. The event, which took place in some real location at a particular time, now exists as a digital cue (e.g., video of the event) on the platform which serves as its new location. We explore two themes through this metaphor. The first concerns the perceived pressure to be on social media and the perception that one misses out on gratifying experiences when one isn't. The second concerns the tension between digital dualism and augmented reality.

As social media platforms increasingly became central meeting hubs on the world wide web (i.e., town squares), they gained prominence as places where one must be. This is well reflected in the rapid growth of platform user communities before 2010 - in 2009 Facebook was growing by a staggering five million users every week [14]. This trend solidified the belief, particularly among first-world adolescent populations, that having a social media profile is an essential dimension of one's social life [25]. The broad adoption of this belief can be ascribed to an iterative relationship between, firstly, the advancement and diversification of the affordances of social media platforms, and secondly, their increasing primacy in the dynamics of real (offline) social networks. The effect was the transformation of social media from a little known cafe mainly frequented by students to the town square. This transformation strengthened the perception that one had to be there, firstly, because everyone else is there and, secondly, to engage in the important and gratifying experiences it offers.

Extending from this belief is the view that missing out on events occurring on social media is undesirable, raising anxiety about this possibility among users. Much like being away from the town square and the exciting or gratifying experiences it offers, being offline is equated to not being physically present at important events. Scholars have explored this theme under the banner of FoMo or fear of missing out, defined as "pervasive apprehension that others might be having rewarding experiences from which one is absent" [28]. As can be expected, experiences of FoMo are associated with increased social media use [2,28], creating a positive feedback loop which solidifies the belief that life happens in the town square. More recently, Reinecke et al. [29] use the term "online vigilance" to describe "users' permanent cognitive orientation towards online content and communication as well as their disposition to exploit these options constantly".

An important feature of likening social media to a physical location is that it draws attention to the distinction between digital dualism and augmented reality. Digital dualists argue that "the digital world is virtual and the physical world real", while the notion of augmented reality suggests that the digital and physical become increasingly meshed through our permanently online, 
permanently connected lives [17]. The ubiquity of mobile computing devices implies that we always have the town square in our pockets, enabling us to switch from uneventful experiences on the edge of town (i.e., being offline) to exciting and rewarding social media experiences. We can continuously be in two or more places at once. By framing social media as a physical location, the metaphor forces us to critically consider this meshing of multiple realities and its effects for identity and well-being. The argument that such switching involves the augmentation of physical reality implies that cues from the physical and digital realities are continuously related to each other and, for the individual, meshed into a single reality. It is conceivable that this premise may hold in some media use scenarios, but it is equally conceivable that there are many in which it may not.

Extending from the notion of rapid switching between physical and digital cues, the metaphor of the town square also draws attention to communication and information load, and the manner in which users' attentional resources are vied for. The volume of sensory cues experienced when moving through a bustling town square requires continuous filtering of environmental stimuli and selection of attentional targets. Within the context of social media business models, the phrase "attention economy" [22] is often used to emphasise the primacy of controlling users' attentional allocation in achieving growth. This has cultivated interest in the science of persuasive design techniques focused on increasing both the frequency and duration of social media use, the principles of which are effectively applied on social media platforms. Much like those moving through the town square are confronted with attention seeking traders and artists, social media platforms employ various techniques in an attempt to manipulate users' attentional allocation decisions. The increase in time spent on social media platforms indicates that these techniques have been particularly effective, prompting researchers to investigate the nature and consequences of problematic social media use, and debate the possibility of social media addiction [1].

\subsection{Social Media as a Beauty Pageant}

Our second metaphor likens social media to a beauty pageant. Through this metaphor we draw attention to two distinct roles which social media users continuously play. The first role is that of participant and concerns the manner in which social media affordances enable the presentation of the self. The second role is that of judge (or audience member) and concerns the manner in which social media platforms facilitate and encourage both social comparison and selfevaluation. We use the metaphor to emphasise how the creation and maintenance of a social media profile can be viewed as a form of "social comparison and interpersonal feedback-seeking" [24]. While these behaviours are considered a normal dimension of identity development, we argue that the ubiquity, pervasiveness and affordances of social media platforms have, firstly, increased their frequency of and, secondly, changed their nature.

Participants in beauty pageants compete against each other on the basis of physical appearance, self-presentation and, more recently, other personal traits. Users of social media platforms, in a comparable way, present themselves to an 
audience (e.g., their connections). These presentations include, on a basic level, the creation and maintenance of a profile, but the affordances of social media platforms enable users to compete using "several techniques to optimise their self-presentation and promote desired relationships", including carefully edited messages and selected images, highlighting positive attributes, presenting an ideal self, deep self-disclosure, and association with certain people or material objects $[4$, p. 117]. The beauty pageant metaphor prompts us to consider these actions as carefully planned attempts to impress other users who are perceived to be continually judging their network. Moreover, it makes explicit the existence of a competitive dimension in social media use, emphasising, by extension, the notion that there are winners and losers. These ideas have received ample attention from scholars investigating the subjective and social underpinnings of self presentation or image crafting by social media users. Narcissism has, for instance, been associated with higher levels of social activity on social media platforms and the creation of more self-promoting content [3]. Halpern et al. [13] found that the online sharing of flattering images of oneself creates the perception, for the sharer, of an online ideal persona that diverges from real-life self-perception.

In addition to enabling social media users to compete in the pageant by presenting themselves, platform affordances enable and encourage users to judge each other. Features such as liking, retweeting and commenting are used by judges to provide contestants with feedback. Importantly, platforms present this feedback to contestants in quantitative form enabling comparison with other contestants, thereby determining ranking among them. In a qualitative study by Fox and Moreland [8, p. 172], interviewees highlight this competitive dimension by comparing the process of getting friends on Facebook to an arms race.

The beauty pageant metaphor also draws attention to the manner in which cycles of presentation and judgement shape social networks. The network, through these feedback loops, continually determines standards and norms which, in turn, influence users' future behaviours. Second, these standards are determined by the particular properties of the network in which the contestants participate. For example, the judging criteria applied among members of a teenage gaming community would be different from those applied among a group of middle-aged golfing friends. Third, building upon the first two, an individual's degree of social (media) capital, by extension, may differ substantially across the various networks he or she competes in.

An important implication of continuously competing is that it cultivates self-judgement. For example, Fox and Moreland [8, p. 172] report that "participants in romantic contexts, wherein they would use Facebook's affordances of persistent history and connectivity to self-compare with a romantic interest's potential or former mates". Importantly, self-judgement is not limited to quantitative indicators (e.g., numbers of followers, friends, likes etc.), but also involves qualitative comparison of experiences, achievements, property etc. In order to beat their competitors, social media users seek ways to enhance their profiles by sharing content that emphasises their own achievements or experiences. The 
metaphor brings to the fore the degree to which this crafting of an image can become a false representation of the actual lived experience of an individual, created for the purpose of winning the pageant.

While acknowledging the potential benefits for self-esteem of positive feedback from judges, a growing body of studies have emphasised the role of social comparison and self-judgement in explaining findings which associate social media use with negative well-being outcomes [19].

\subsection{Social Media as a Parliament}

Our third metaphor adopts the notion of a parliament as source domain. Parliaments, as government institutions, generally perform a number of functions relating to the governance of democratic countries by representing the electorate. These functions may include, amongst others, making laws, overseeing the executive and representing the interests, views and grievances of citizens. Parliaments are typically constituted by elected members, and their activities are managed, at various levels, by political leaders, parliamentary officials, presiding officers and committee chairs. Political deliberation or debate is a key feature of parliaments. Winetrobe [35, p. 1], accordingly, describes them as "forums where strong, very public, and often adversarial political debates take place, reflecting the party competition of the wider political system".

We argue that social media platforms, like parliaments, provide a context which enables deliberation among members of their user communities. Deliberation involves the "interchange of rational critical arguments among a group of individuals, triggered by a common or public problem" [12]. Importantly, our interest in the source domain is not the content of deliberation (i.e., political debate), but rather the nature of the context in which deliberation occurs, the mechanisms (and affordances) by which it is guided, and the manner in which it impacts network structures. The metaphor, accordingly, is as relevant to political debate on social media platforms as it is to deliberation about sports teams, stock markets, or the duties of the local neighbourhood watch.

The affordances of social media platforms enable users to organise themselves into smaller networks based on commonalities (e.g., shared interests, place of residence, occupation etc.). These sub-committees do not, per definition, involve exclusive access to members. For example, on a platform like Twitter, one can consider deliberation around particular hashtags as a sub-committee. All Twitter users can, from the public gallery, view the deliberation activities without (necessarily) taking an active role. Much like the sub-committees of parliaments, these smaller networks deliberate aspects specific to their commonality. Additionally, the affordances of some platforms enable communities to assign roles (e.g., administrators, moderators etc.) to specific members who, like those managing parliamentarian processes, have particular rights and privileges that enable them to perform managerial or administrative activities during deliberation among members. Importantly, just as not all members of parliament are considered equal in terms of political capital, there exists asymmetry in influence among social media users due to a wide variety of factors [22]. 
de Zúñiga et al. [36] argue that the processes of obtaining and using social capital on social media differs in nature from those relating to social capital in face-to-face settings. They argue that "social media has changed the structure and nature of social connection, and therefore that they may alter the distribution and nature of social capital embedded in those social relationships" [36, p. 45]. In this regard the metaphor draws our attention to the processes of deliberation within social media communities, and the interplay between deliberation, user behaviour and community structures. On many social media platforms users, like parliamentarians, do not address a particular target but rather the community as a whole. Community members are then free to respond to the content, creating a thread of deliberation. In addition to liking or retweeting the statement presented, affordances enable engagement through responses, counter-arguments or supportive comments. These forms of feedback enable the community to gauge the degree of support for particular viewpoints and determine the alignment between their personal views and those of other members. On this basis factions or alliances emerge which, in turn, drive the disintegration of existing, and formation of new networks.

A theme which has received ample attention from scholars is the role of homophily, "the tendency to favour interaction with like-minded people" [10], in network formation on social media platforms. The product, when this tendency is enacted, is the formation of echo chambers - communities in which users are only exposed to ideas aligning with their own. Gayo-Avello [10] argues that while social media users have "a certain degree of exposure to cross-cutting ideas (even to users who are clearly partisans) and can interact with users who have opposing ideas", they mostly avoid such discussions. Additionally, his research suggests that when users encounter arguments that are in conflict with their views, they do not propagate them within their networks. This theme has primarily been explored in the context of political polarisation where a key concern is the manner in which online deliberation reinforces preexisting views by perpetuating a confirmation bias [5]. However, contrary findings have also been reported. For example, Semaan et al. [32] found that some social media users purposefully seek diverse information and discussants and that such interactions often lead to alterations of personal views. This form of use aligns, in many ways, with the ethos of parliamentary deliberation.

\subsection{Social Media as a Masquerade Ball}

Our final metaphor likens social media to a masquerade ball. We envision a masquerade ball as a social event where attendees obscure, to a lesser or greater degree, their true identities by wearing a mask or costume. Social interaction, accordingly, occurs under conditions of some degree of anonymity. The dynamics of behaviour and interaction are influenced by this property, creating an element of excitement and novelty to the event. This excitement can be attributed to liberation from the constraints associated with the presentation and maintenance of a single, true identity. Scott and Orlikowski [31, p. 5] argue that "anonymity is related to freedom from identification, secrecy and lack of distinction". 
We propose that, like the masks or constumes worn to masquerade balls, social media affordances enable users to obscure their identities to achieve some degree of freedom from the constraints associated with the maintenance of a socially acceptable personal identity. This freedom affords users the opportunity to pursue interests or engage in behaviour online which may, for various reasons, be inaccessible to or incongruent with their true identity. Research has shown that anonymity impacts the behaviour on social media in various ways [12] and that some social media platforms (e.g., Reddit and 4/chan/) leverage anonymity, "as a design choice", to influence online interaction and norms [21, p. 3857]. Importantly, the metaphor (as we intend it) is not concerned with fake accounts or bots which we consider to be a separate domain of interest.

Anonymity encourages deindividuation, allowing people to be less self aware, engage less in self-evaluation and be less "concerned about social comparison and evaluation" [27, p. 138]. As a result, behaviour becomes "socially deregulated" [12, p. 2]. Findings suggest that such deregulation is associated less polite interaction. Halpern and Gibbs [12], for example, found that messages posted on YouTube, which is generally more anonymous, were more impolite than messages in the "more identifiable Facebook medium". They argue that this occurs "due to the greater level of information access to users' broader social networks" on Facebook. Additionally, anonymity has been associated with higher levels of self-disclosure on social media [21]. Pavalanathan [26, p. 315], for example, investigates the role of anonymity in the use of online fora concerning mental health, arguing that users "withhold their actual identities allowing themselves to engage in more candid self-disclosure than is possible in offline settings, or through their identified online personas".

While image crafting, as a dimension of the beauty pageant metaphor, draws attention to how users emphasise or highlight aspects of their identities, the masquerade ball draws our attention to the manner in which image crafting also involves obscuring of identity aspects. In this way the two metaphors describe how the same outcome (i.e., desired self-presentation) can be achieved through different strategies (i.e., accentuating vs obscuring). The masks worn at masquerade balls may not fully obscure the person, but be carefully chosen to hide particular physical features. We argue, accordingly, that social media users carefully utilise affordances, like masks, to find an optimal balance between disclosure and anonymity based on their goals and the nature of the social media space. Guadagno et al. [11] use the phrase "deceptive self-presentation" to describe such behaviour and argue that "it increases as a function of the pressure to engage in self-presentation" [11, p. 642]. Alternatively, users may wish to disclose personal information but avoid identifiability. For example, users of online dating platforms may, due to the stigma traditionally associated with the practice [7], obscure information making them identifiable, but disclose aspects like physical appearance to attract attention to their profiles. It is our view that these and other forms of masquerading have become salient features of social media logic, with broad adoption serving to obscure their novelty and significance. The metaphor brings them to the fore and invites critical reflection about their enactment and effects. 


\section{Discussion}

In this paper we explored four metaphors of social media with the aim of elucidating particular dimensions of social media logic - the norms, strategies, and economics underpinning its dynamics. It is our view that the four metaphors presented here provide an initial indication of the potential value of utilising metaphor in the analysis and communication of social media logic. We foresee two specific contexts where this value can be realised.

The first is teaching and, in particular, teaching to digital natives for whom chronic social media use is the norm. For such individuals the dynamics of behaviour and network formation on social media may be so embedded in their understanding of social interaction in general that they may altogether disregard the agency of the technical affordances of social media platforms in their behaviour. Metaphors of non-mediated social spaces will enable educators to draw students' attention to the role of these affordances in shaping mediated socialisation patterns and the extent to which they determine behavioural norms on social media platforms.

The second context where these metaphors can be of value is the communication of scientific findings to non-scientific stakeholder groups. For example, therapists or psychologists can utilise the beauty pageant metaphor to help their clients to make sense of the role social media use may play in processes of self-esteem updating. School teachers and parents can use the town square metaphor to encourage adolescents to critically reflect about their attention allocation habits and the impacts chronic media multitasking on academic and other performance.

Importantly, while the four metaphors presented here may provide a useful starting point, they are obviously limited in scope and only cover a small subset of social media phenomena that have been investigated. For example, one may argue that none of our metaphors adequately addresses underlying business models of social media platforms, and how these models drive, firstly, the development of affordances and, secondly, user behaviour. Other prominent themes which are not explicitly addressed include cyberbullying, marketing through influencers and compulsive or problematic social media use. To address these and other themes, future work in this area can consider metaphors in relation to the seven functional blocks of social media as proposed by Kietzmann et al. [18].

\section{References}

1. Andreassen, C.S.: Online social network site addiction: a comprehensive review. Curr. Addict. Rep. 2(2), 175-184 (2015). https://doi.org/10.1007/s40429-0150056-9

2. Beyens, I., Frison, E., Eggermont, S.: "I don't want to miss a thing": adolescents' fear of missing out and its relationship to adolescents' social needs, facebook use, and facebook related stress. Comput. Hum. Behav. 64, 1-8 (2016)

3. Buffardi, L.E., Campbell, W.K.: Narcissism and social networking web sites. Pers. Soc. Psychol. Bull. 34(10), 1303-1314 (2008) 
4. Chou, H.T.G., Edge, N.: "They are happier and having better lives than I am": the impact of using facebook on perceptions of others' lives. Cyberpsychology Behav. Soc. Netw. 15(2), 117-121 (2012)

5. Davis, R.: The Web of Politics: The Internet's Impact on the American Political System. Oxford University Press, Oxford (1999)

6. van Dijck, J., Poell, T.: Understanding social media logic. Media Commun. 1(1), 2-14 (2013)

7. Finkel, E.J., Eastwick, P.W., Karney, B.R., Reis, H.T., Sprecher, S.: Online dating. Psychol. Sci. Public Interest 13(1), 3-66 (2012)

8. Fox, J., Moreland, J.J.: The dark side of social networking sites: an exploration of the relational and psychological stressors associated with Facebook use and affordances. Comput. Hum. Behav. 45, 168-176 (2015)

9. Franke, W.: Metaphor and the making of sense: the contemporary metaphor renaissance. Philos. Rhetor. 33(2), 137-153 (2000)

10. Gayo-Avello, D.: Social media, democracy, and democratization. IEEE Multimed. 22(2), 10-16 (2015)

11. Guadagno, R.E., Okdie, B.M., Kruse, S.A.: Dating deception: gender, online dating, and exaggerated self-presentation. Comput. Hum. Behav. 28(2), 642-647 (2012)

12. Halpern, D., Gibbs, J.: Social media as a catalyst for online deliberation? Exploring the affordances of Facebook and YouTube for political expression. Comput. Hum. Behav. 29(3), 1159-1168 (2013)

13. Halpern, D., Katz, J.E., Carril, C.: The online ideal persona vs. the jealousy effect: two explanations of why selfies are associated with lower-quality romantic relationships. Telemat. Inform. 34(1), 114-123 (2017)

14. Hempel, J.: How Facebook is taking over our lives. Fortune 159(4), 48-56 (2009)

15. Holyoak, K.J., Stamenković, D.: Metaphor comprehension: a critical review of theories and evidence. Psychol. Bull. 144(6), 641-671 (2018)

16. Hung, D.W.L.: Metaphorical ideas as mediating artifacts for the social construction of knowledge: implications from the writings of Dewey and Vygotsky. Int. J. Instr. Media 29, 197+ (2002)

17. Jurgenson, N.: Digital dualism versus augmented reality. The Society Pages (2011)

18. Kietzmann, J.H., Hermkens, K., McCarthy, I.P., Silvestre, B.S.: Social media? Get serious! Understanding the functional building blocks of social media. Bus. Horiz. 54(3), 241-251 (2011)

19. Krause, H.V., Baum, K., Baumann, A., Krasnova, H.: Unifying the detrimental and beneficial effects of social network site use on self-esteem: a systematic literature review. Media Psychol. 1-38 (2019)

20. Lakoff, G.: A figure of thought. Metaphor. Symb. Act. 1(3), 215-225 (1986)

21. Ma, X., Hancock, J., Naaman, M.: Anonymity, intimacy and self-disclosure in social media. In: Proceedings of the 2016 CHI Conference on Human Factors in Computing Systems - CHI 2016, pp. 3857-3869 (2016)

22. Marwick, A.E.: Instafame: luxury selfies in the attention economy. Public Cult. $\mathbf{2 7}(1(75))$, 137-160 (2015)

23. Morgan, G.: Images of Organization. Sage Publications, London (2006)

24. Nesi, J., Prinstein, M.J.: Using social media for social comparison and feedbackseeking: gender and popularity moderate associations with depressive symptoms. J. Abnorm. Child Psychol. 43(8), 1427-1438 (2015). https://doi.org/10.1007/s10802015-0020-0 
25. Parry, D.A., le Roux, D.B.: Off-task media use in lectures: towards a theory of determinants. In: Kabanda, S., Suleman, H., Gruner, S. (eds.) SACLA 2018. CCIS, vol. 963, pp. 49-64. Springer, Cham (2019). https://doi.org/10.1007/978-3-03005813-5_4

26. Pavalanathan, U.: Identity management and mental health discourse in social media identity in online communities. In: International World Wide Web Conference Committee (IW3C2), vol. 18, no. 22, pp. 315-321 (2015)

27. Polder-Verkiel, S.E.: Online responsibility: bad samaritanism and the influence of internet mediation. Sci. Eng. Ethics 18(1), 117-141 (2012). https://doi.org/10. 1007/s11948-010-9253-z

28. Przybylski, A.K., Murayama, K., Dehaan, C.R., Gladwell, V.: Motivational, emotional, and behavioral correlates of fear of missing out. Comput. Hum. Behav. 29(4), 1841-1848 (2013)

29. Reinecke, L., et al.: Permanently online and permanently connected: development and validation of the online vigilance scale. PloS One 13(10) (2018)

30. Ricoeur, P.: The metaphorical process as cognition, imagination, and feeling. Crit. Inq. 5(1), 143-159 (1978)

31. Scott, S.V., Orlikowski, W.J.: Entanglements in practice: performing anonymity through social media. MIS Q. 38(3), 873-893 (2014)

32. Semaan, B., Robertson, S.P., Douglas, S., Maruyama, M.: Social media supporting political deliberation across multiple public spheres: towards depolarization. In: Proceedings of the ACM Conference on Computer Supported Cooperative Work, CSCW, pp. 1409-1421 (2014)

33. Shen, Y.: Principles of metaphor interpretation and the notion of 'domain': a proposal for a hybrid model. J. Pragmat. 31(12), 1631-1653 (1999)

34. Van Engen, R.B.: Metaphor: a multifaceted literary device used by Morgan and Weick to describe organizations. Emerg. Leadersh. Journeys 1(1), 39-51 (2008)

35. Winetrobe, B.K.: Political but not partisan: marketing parliaments and their members. J. Legis. Stud. 9(1), 1-13 (2003)

36. de Zúñiga, H.G., Barnidge, M., Scherman, A.: Social media social capital, offline social capital, and citizenship: exploring asymmetrical social capital effects. Polit. Commun. 34(1), 44-68 (2017) 